\title{
Extended Wing Technique Approach for the Detection of Winding Interturn Faults in Three-phase Transformers
}

\author{
Makarand Sudhakar Ballal ${ }^{\dagger}$, Hiralal Murlidhar Suryawanshi ${ }^{*}$, and Bhupesh Nemichand Choudhari ${ }^{* *}$ \\ $\dagger^{*}$ Department of Electrical Engineering, Visvesvaraya National Institute of Technology, Nagpur, India \\ ${ }^{* *}$ Department of Electrical Engineering, P. E. S. College of Engineering, Aurangabad, India
}

\begin{abstract}
This paper presents a novel approach to diagnose interturn insulation faults in three-phase transformers that operate at different loading conditions. This approach is based on the loci of instantaneous symmetrical components and requires the measurement of three input primary winding currents and voltages to diagnose faults in the transformer. The effect of unbalance supply conditions, load variations, constructional imbalance, and measurement errors when this methodology is used is also investigated. Wing size or length determines the loading on the transformer. Wing travel and area determine the degree of severity of fault. Experimental results are presented for a 400/200 V, $7.5 \mathrm{kVA}$ transformer to validate this method.
\end{abstract}

Keywords: Interturn faults, Locus of current, Transformer

\section{INTRODUCTION}

Transformers are critical components of the energy transmission and distribution process for electric utilities. Interturn winding insulation faults lead to generated heat in the defective region of the winding. This generated heat causes the fault to progress rapidly to more severe forms, such as phase-to-phase and phase-to-ground faults. These faults may cause gradual deterioration of the transformer winding if they are not detected at an early stage, which results in downtime and financial losses. Therefore, it is always desirable to detect and diagnose these kinds of incipient faults at their very inception stage. In [1], an online technique is introduced to detect the internal faults within a power transformer by constructing the voltage-current locus diagram to provide a current state of the transformer. The technique does not need any new hardware since it uses the existing metering devices attached to the power transformer. Furthermore, the method is implemented online because it is performed at the power frequency. The characteristic signatures associated with the

Manuscript received Mar. 28, 2014; accepted Jul. 31, 2014

Recommended for publication by Associate Editor Jin Hur.

†Corresponding Author: msb_ngp@rediffmail.com

Tel: +91-712-2801147, Fax: +91-712-2223230, Visvesvaraya Nat'1 Inst. of Tech.

${ }^{*}$ Dept. of Electrical Eng., Visvesvaraya National Inst. of Tech., India

${ }^{* *}$ Dept. of Electrical Engineering, P. E. S. College of Engineering, India interturn faults derived from the simulation results and the experimental tests are discussed in [2]. The results of the experiments on the transformer demonstrate the ability of the finite element model (FEM) to reproduce the real behavior of the transformer in both healthy and faulty conditions. The technique discussed in [3] represents the transformer with turn-to-earth fault using a healthy transformer with new short circuit impedance. This turn-to-earth fault is represented as an external line to ground fault. The results of the technique based on the symmetrical component method are compared with those obtained using the EMTP/ATP program. Article [4] proposes an algorithm for protection, identification of a faulted phase and winding of the three-phase winding transformer using the increments of flux linkages.

Conventional and advanced transformer winding deformation diagnosis methods are discussed in [5]. The mechanical defect in transformer active part is investigated as a crucial problem in this key feature to provide an insight into related issues. The criteria for detection of low-level short circuit faults using the sweep frequency response analysis (SFRA) measurements on the distribution transformer windings is described in [6]. A FEM of the tested transformer is used to justify the response as a result of the fault occurrence. The normal and faulty responses of the transformer windings damaged by the interturn faults are reflected in the spectrum 
deviation as compared to the correlation coefficient.

An arc discharge model used to simulate the arcing phenomena between two adjacent discs of transformer winding during impulse test is discussed in [7]. An analysis of the currents that arise during a turn-to-turn fault in the transformer, in which a winding is delta connected, through finite element simulations is presented in [8]. The approach is based on the analysis of current sequences that appear in the fault state, and mainly in the nature of a zero sequence current (ZSC) in a delta winding. The influence of the short-circuit resistance, load power factor, fault location, and the value of load have been considered and analyzed.

The application of the on-load exciting current extended Park's vector approach to diagnose the occurrence of interturn short circuits in the windings of operating three-phase transformers is presented in [9]. This technique combines the three methods i.e. the former Park's Vector Approach, which combines the information contained in the three phase system into only one quantity; the on load exciting current, which enhances the fault detection sensitivity; and the spectral analysis, which gives detailed insight into the results obtained by the Park's Vector.

The contribution of [10] illustrates how to realize online monitoring of power transformers in service using the transfer function method for detecting winding interturn faults. The transfer function (TF) variations caused by the interturn faults based on the lumped circuit model is discussed in [11]. The variation of the amplitude in resonance frequencies indicates an increment in the consumed energy in the early stage as the fault develops and vice versa. The sensitivity of the TF method to interturn fault is determined by the network impedance between the shorted nodes, which approximates the self inductance of the shorted turn in continuous winding. The physical behavior of the power transformers in the presence of interturn faults obtained in [12]. Characteristic fault signatures associated with the interturn faults derived for different load conditions. It is observed that, under full load conditions reduced supplying voltage and incipient stages of low level interturn faults, there was no remarkable change in the primary current of the transformer because the effect of the fault is too small when compared to the transformer larger load currents.

The development and implementation of a permeance-based transformer model to analyze the permanent and intermittent winding insulation faults are described in [13]. The on-load exciting current Park's vector approach is applied to diagnose the occurrence of intermittent interturn short circuits in the transformer windings. The "Wing Technique" approach based on the symmetrical components is applied to detect the interturn short circuit fault in three phase induction motor is discussed in [14].

In this article, the "Wing Technique" approach [14] is extended for the detection of the interturn short circuit fault in both the primary as well as secondary winding of three phase transformer. Model of 400/200 V, $7.5 \mathrm{kVA}$ transformer is developed in laboratory. Interturn short circuit fault is experimentally simulated by shorting the primary and secondary winding turns. For this purpose both the side winding turns are taken out. The input currents of all the three phases are considered to plot the loci by symmetrical component method. The positive and negative components loci are used to design wing shape structure. The size or length of wings predicts the loading on the transformer and the area of wings and their travel predicts the degree of severity of fault. This technique is immune to voltage imbalance variation, load imbalance as well as it considers inherent asymmetry and measurement errors.

\section{RELATION OF TRANSFORMER WINDING INTERTURN FAULT WITH INTAKE CURRENT AND IMPEDANCE}

A three-phase winding $Y-Y$ transformer Fig. 1(a) is considered to explain the concept. The setup is described by the set of equations that follows. Subscripts 1 and 2 denote the primary and secondary parameters. Subscripts $a, b$, and $c$ indicate the three phases of the power system. The primary voltages and currents are depicted by $v_{1 a}, v_{1 b}$, and $v_{1 c}$, and $i_{1 a}$, $i_{1 b}$, and $i_{1 c}$ for each phase, respectively. The secondary voltages and currents are depicted by $v_{2 a}, v_{2 b}$, and $v_{2 c}$ and $i_{2 a}$, $i_{2 b}$, and $i_{2 c}$ for each phase, respectively. The secondary side load terminal voltages are represented by $v_{2 l a}, v_{2 l b}$, and $v_{2 l c}$ for the three phases.

The primary and secondary winding turns of the transformer are represented by $N_{1(a, b . c)}$ and $N_{2(a, b . c)}$, respectively. Accordingly, $N_{1 a}=N_{1 b}=N_{1 c}=N_{1} \quad$ and $N_{2 a}=N_{2 b}=N_{2 c}=N_{2}$ are expected but not possible because of the constructional asymmetry in practice. Therefore, the transformation ratio of each phase will be different. These ratios are $k_{a}=N_{1 a} / N_{2 a}, k_{b}=N_{1 b} / N_{2 b}$, and $k_{c}=N_{1 c} / N_{2 c}$ for the respective phases. The no-load primary currents drawn from the respective three phases are used to magnetize the transformer and supply the hysteresis and eddy current losses. This No-load primary current is modeled using two components, namely, resistances $\left(R_{c a}, R_{c b}\right.$, and $\left.R_{c c}\right)$ and inductances ( $L_{l m a}, L_{l m b}$, and $L_{l m c}$ ) across the primary for the respective three phases as shown in Fig. 1(b). The magnetizing current lags the applied voltage by $90^{\circ}$. The sets of resistive components $\left(R_{1 a}, R_{1 b}\right.$, and $R_{1 c}$ and $R_{2 a}, R_{2 b}$, and $R_{2 c}$ ) refer to the primary and secondary sides, respectively. Similarly, the sets of inductive components $\left(L_{l 1 a}, L_{l 1 b}\right.$, and $L_{l 1 c}$ and $L_{l 2 a}, L_{l 2 b}$, and $L_{l 2 c}$ ) denote the primary and secondary sides, respectively.

All the elements in a reactance diagram are referred to as either the primary or the secondary side of the transformer to simplify calculations. The secondary impedance in this study refers to the primary side (i.e., $Z_{r 1(a, b, c)}$ ) presented as follows: 


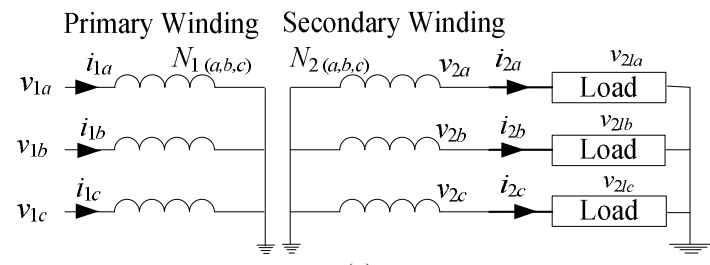

(a)

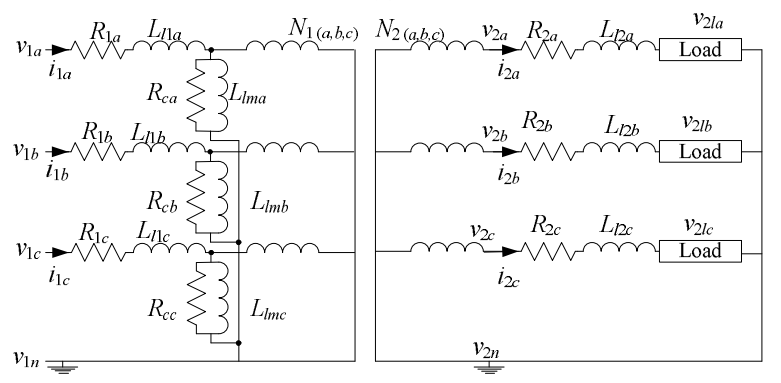

(b)

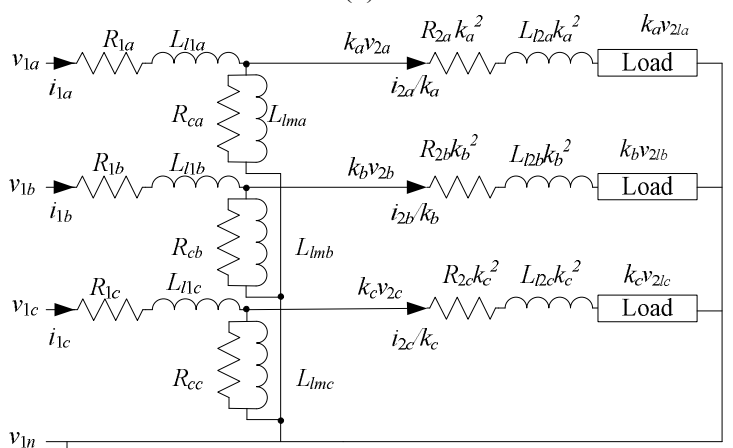

(c)
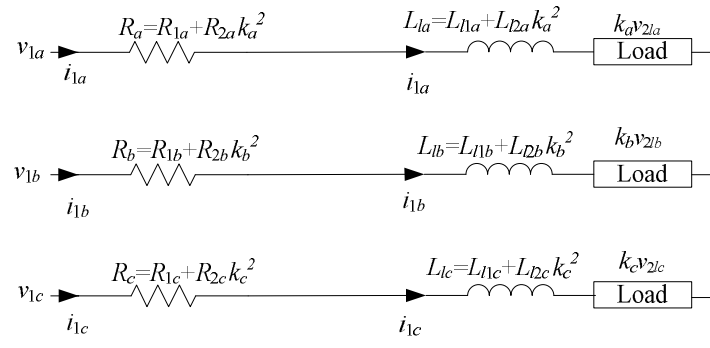

(d)

Fig. 1. (a) Y-Y transformer connection; (b) transformer model; (c) equivalent circuit diagram referred to as primary; and (d) equivalent circuit diagrams ignoring the magnetizing component.

$$
Z_{r 1(a, b, c)}=\frac{V_{1(a, b, c)}}{I_{1(a, b, c)}}=\frac{V_{2(a, b, c)}\left(N_{1(a, b, c)} / N_{2(a, b, c)}\right)}{I_{2(a, b, c)}\left(N_{1(a, b, c)} / N_{2(a, b, c)}\right)}
$$

Where, $V_{1(a, b, c)}, V_{2(a, b, c)}$ and $I_{1(a, b, c)}, I_{2(a, b, c)}$ are the rms values of voltages and currents referred to primary and secondary respectively for the corresponding phases. The equivalent circuit with all elements referred to primary is shown in Fig 1(c). Such a complete equivalent circuit is not necessary in most of the calculations. Therefore, the circuit is simplified by omitting the shunt magnetizing branches and combining all the series resistors and inductances into one equivalent as shown in Fig. 1(d) referred to primary. The equivalent resistances $\left(R_{a}, R_{b}\right.$, and $\left.R_{c}\right)$ and equivalent inductances ( $L_{l a}$, $L_{l b}$, and $L_{l c}$ ) are referred to the primary side of the transformer. Similarly, the load terminal voltages are referred to primary side and represented by $k_{a} v_{2 l a}, k_{b} v_{2 l b}$, and $k_{c} v_{2 l c}$ for the respective three phases. From the Fig. 1(d), the voltages of the primary windings can be represented by following set of equations

$$
\begin{aligned}
& \boldsymbol{v}_{1 a}=R_{a} \boldsymbol{i}_{1 a}+L_{l a} \frac{d \boldsymbol{i}_{1 a}}{d t}+k_{a} \boldsymbol{v}_{2 l a} \\
& \boldsymbol{v}_{1 b}=R_{b} \boldsymbol{i}_{1 b}+L_{l b} \frac{d \boldsymbol{i}_{1 b}}{d t}+k_{b} \boldsymbol{v}_{2 l b} \\
& \boldsymbol{v}_{1 c}=R_{c} \boldsymbol{i}_{1 c}+L_{l c} \frac{d \boldsymbol{i}_{1 c}}{d t}+k_{c} \boldsymbol{v}_{2 l c}
\end{aligned}
$$

Therefore, the primary currents derived from these equations are given by the following set of equations:

$$
\begin{aligned}
& \boldsymbol{i}_{1 \boldsymbol{a}}=\frac{\boldsymbol{v}_{1 \boldsymbol{a}}-k_{a} \boldsymbol{v}_{2 l a}}{R_{a}}+K_{a} e^{-\left(\frac{R_{a}}{L_{l a}}\right) t} \\
& \boldsymbol{i}_{1 \boldsymbol{b}}=\frac{\boldsymbol{v}_{1 b}-k_{b} \boldsymbol{v}_{2 l b}}{R_{b}}+K_{b} e^{-\left(\frac{R_{b}}{L_{l b}}\right) t} \\
& \boldsymbol{i}_{1 \boldsymbol{c}}=\frac{\boldsymbol{v}_{1 c}-k_{c} \boldsymbol{v}_{2 l c}}{R_{c}}+K_{c} e^{-\left(\frac{R_{c}}{L_{l c}}\right) t}
\end{aligned}
$$

Where, $K_{a}, K_{b}$ and $K_{c}$ are the respective constants values for three phases. In this study, the source voltages $\left(v_{1 a}, v_{1 b}, v_{1 c}\right)$ and load voltages $\left(k_{a} v_{2 l a}, k_{b} v_{2 l b}, k_{c} v_{2 l c}\right)$ are made constant, therefore the input currents $\left(i_{1 a}, i_{1 b}, i_{1 c}\right)$ are depends upon the values of respective resistances $\left(R_{a}, R_{b}, R_{c}\right)$ and inductances $\left(L_{l a}, L_{l b}, L_{l c}\right)$ only. The equivalent impedances referred to primary for the respective three phases are given as

$$
\begin{aligned}
& \boldsymbol{Z}_{\boldsymbol{a}}=R_{a}+j \omega L_{l a} \\
& \boldsymbol{Z}_{\boldsymbol{b}}=R_{b}+j \omega L_{l b} \\
& \boldsymbol{Z}_{\boldsymbol{c}}=R_{c}+j \omega L_{l c}
\end{aligned}
$$

In a three phase connection for solidly ground, $\mathrm{Y}-\mathrm{Y}$ connected transformer, the sum of the phase currents must be zero for balanced three phase system, i.e.,

$$
\boldsymbol{I}_{1 \boldsymbol{a}}+\boldsymbol{I}_{1 \boldsymbol{b}}+\boldsymbol{I}_{1 \boldsymbol{c}}=0
$$

Where, $I_{1 a}, I_{1 b}$ and $I_{1 c}$ are the rms values of respective phase currents referred to primary. We have assumed here, $k_{a} v_{2 l a}=v_{l a}, k_{b} v_{2 l b}=v_{l b}$, and $k_{c} v_{2 l c}=v_{l c}$. Let $V_{1 a}, V_{1 b}$ and $V_{1 c}$ are the rms values of source voltages and $V_{1 l a}, V_{1 l b}$ and $V_{1 l c}$ are the rms values of load terminal voltages refer to primary. Therefore, equation (5), can be written as,

$$
\frac{\boldsymbol{V}_{1 \boldsymbol{a}}-\boldsymbol{V}_{1 \boldsymbol{l a}}}{Z_{a}}+\frac{\boldsymbol{V}_{1 \boldsymbol{b}}-\boldsymbol{V}_{1 \boldsymbol{l b}}}{Z_{b}}+\frac{\boldsymbol{V}_{1 \boldsymbol{c}}-\boldsymbol{V}_{1 \boldsymbol{l} \boldsymbol{c}}}{Z_{c}}=0
$$

This condition gets satisfied only if voltage differences as 
well as impedances values remain constants. The rms value of input current referred to primary of particular phase at angle $\theta_{a}$, say for phase $a$, is normal under healthy condition and expressed as

$$
I_{1 a} \angle \theta_{1 a}=\frac{\boldsymbol{V}_{1 \boldsymbol{a}}-\boldsymbol{V}_{1 \boldsymbol{l a}}}{Z_{a}}
$$

Let the transformer primary winding has $N_{1 a}$ number of turns having total impedance of $Z_{a} \Omega$. Therefore, the impedance per turn will be $z_{a}=Z_{a} / N_{1 a}$. The parallel path resistance $r$ exists across the $n_{1 a}$ number of turns if the interturn short-circuit fault occurs across the $n_{1 a}$ number of turns $\left(n_{1 a}<N_{1 a}\right)$. Therefore, the equivalent impedance of this winding reduces to $Z_{a f}$ as follows:

$$
Z_{a f}=\left(N_{1 a}-n_{1 a}\right) z_{a}+\left(n_{1 a} z_{a} r / n_{1 a} z_{a}+r\right)
$$

For example, refer to Fig 2, when the fault appears on primary side between turn No.4 and $5,\left(n_{1 a}=5-4=1\right)$ physically the enamel insulation between these two turns gets destroyed. The insulation of this area weakens. Furthermore, the current starts to penetrate through this newly formed parallel path because of this part. The value of this parallel path resistance $r$ depends on the level of the insulation damage. The $Z_{a f}$ value depends on the number of shorted turns. Hence, the $r$ value appears across the shorted turns. The deviation in the healthy and faulty transformer impedance values pertaining to phase $a$ is given as follows:

$$
\Delta Z_{w a}=\left(Z_{a}\right)-\left(Z_{a f}\right)
$$

This equation is applicable to all phases and both sides of the transformer. This change in the magnitude of $Z_{a}$ increases the input winding current referred to as phase $a$ in the primary side at constant load and voltage conditions. This situation is expressed by the following equation:

$$
I_{1 a f} \angle \phi_{1 a}=\frac{\boldsymbol{V}_{1 \boldsymbol{a}}-\boldsymbol{V}_{1 \boldsymbol{l a}}}{Z_{a f}}
$$

where $\phi_{1 a}$ is the phase angle of the current, and $Z_{a f}$ is the equivalent primary winding impedance under unhealthy (i.e., interturn short circuit) condition. Equations (7) and (10) enable us to write deviation in transformer winding intake current as follows:

$$
I_{1 d a} \angle \delta_{1 a}=I_{1 a f} \angle \phi_{1 a}-I_{1 a} \angle \theta_{1 a}
$$

From (11), it is possible to establish the relation of transformer winding current and winding interturn fault either on primary side or on secondary side. Whenever winding interturn fault occurs, winding intake current varies not only in amplitude but also in phase displacement whenever the winding interturn fault occurs. Consequently, $I_{1 d a}=0$ and $\angle \delta_{1 a}=0$ under the healthy winding condition. A negative sequence current seems to appear from the observation.

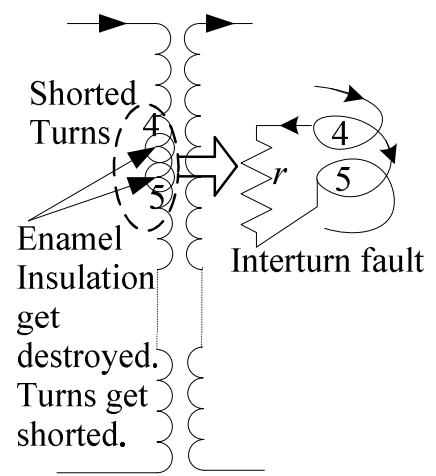

Fig. 2. Interturn short-circuit fault.

Moreover, an imbalance of the transformer intake currents is exhibited because of the interturn short-circuit faults.

The three-phase transformer winding currents referred to primary are given by the following expression:

$$
\begin{aligned}
& \boldsymbol{i}_{1 a}=I_{1 m a} \sin \left(\omega t+\theta_{1 a}\right) \\
& \boldsymbol{i}_{1 b}=I_{1 m b} \sin \left(\omega t-2 \pi / 3+\theta_{1 b}\right) \\
& \boldsymbol{i}_{1 c}=I_{1 m c} \sin \left(\omega t+2 \pi / 3+\theta_{1 c}\right)
\end{aligned}
$$

where $I_{1 m a}, I_{1 m b}$, and $I_{1 m c}$ denote the peak values of the three-phase currents, and $\theta_{1 a}, \theta_{1 b}$, and $\theta_{1 c}$ are the phase unbalance in degrees.

These currents may be unbalanced in magnitude and phase angles. The currents are resolved into zero, positive, and negative sequence currents based on instantaneous symmetrical component theory [14]. These equations are expressed as follows:

$$
\left[\begin{array}{l}
\boldsymbol{i}_{a 0} \\
\boldsymbol{i}_{a 1} \\
\boldsymbol{i}_{a 2}
\end{array}\right]=\frac{1}{3}\left[\begin{array}{ccc}
1 & 1 & 1 \\
1 & a & a^{2} \\
1 & a^{2} & a
\end{array}\right]\left[\begin{array}{l}
\boldsymbol{i}_{1 a} \\
\boldsymbol{i}_{1 b} \\
\boldsymbol{i}_{1 c}
\end{array}\right]
$$

where $a=e^{j 2 \pi / 3}$ is a complex operator. It is mentioned that the instantaneous vector $\boldsymbol{i}_{\boldsymbol{a} 1}$ and $\boldsymbol{i}_{\boldsymbol{a} \mathbf{2}}$ are complex conjugate of each other and $\boldsymbol{i}_{\boldsymbol{a} \mathbf{0}}$ is a real quantity. Also, $\boldsymbol{i}_{\boldsymbol{a} \mathbf{1}}, \boldsymbol{i}_{\boldsymbol{a} \mathbf{2}}$ and $\boldsymbol{i}_{\boldsymbol{a} \mathbf{0}}$ represents positive, negative and zero sequence components of current phasors respectively. The complex quantities $\boldsymbol{i}_{\boldsymbol{a} \mathbf{1}}$ and $\boldsymbol{i}_{\boldsymbol{a} \boldsymbol{2}}$ can be expressed in terms of voltage difference as below.

$$
\left[\begin{array}{c}
\boldsymbol{i}_{\boldsymbol{a} 1} \\
\boldsymbol{i}_{\boldsymbol{a} 2}
\end{array}\right]=\frac{1}{3}\left[\begin{array}{ccc}
1 & a & a^{2} \\
1 & a^{2} & a
\end{array}\right]\left[\begin{array}{l}
\frac{\boldsymbol{v}_{1 \boldsymbol{a}}-k_{a} \boldsymbol{v}_{2 l a}}{R_{a}}+K_{a} e^{-\left(\frac{R_{a}}{L_{l a}}\right) t} \\
\frac{\boldsymbol{v}_{1 \boldsymbol{b}}-k_{b} \boldsymbol{v}_{2 l b}}{R_{b}}+K_{b} e^{-\left(\frac{R_{b}}{L_{l b}}\right) t} \\
\frac{\boldsymbol{v}_{1 \boldsymbol{c}}-k_{c} \boldsymbol{v}_{2 l c}}{R_{c}}+K_{c} e^{-\left(\frac{R_{c}}{L_{l c}}\right) t}
\end{array}\right]
$$


From (14), a variation is found in the corresponding phase currents whenever a change in the impedance values of any phase pertaining to the primary side because of the interturn short-circuit faults. This change causes an alteration in the positive and negative sequence components of the currents.

\section{EXTENDED WING TECHNIQUE APPLICATION FOR THE DETECTION OF INTERTURN FAULTS OF THE TRANSFORMER}

The only inherent and readily accessible alternative sources of information regarding the health of the transformer are the terminal voltages and intake currents. The wing technique phenomenon applied to detect the interturn fault is explained in [14], where the load is considered symmetrical in all three phases. The wing technique in this paper is further extended to detect the interturn short-circuit fault when the transformer is loaded with different imbalance load conditions.

The unbalance in the magnitude of the currents and the phase angles of the three transformer phases is mainly caused by the unbalanced supply voltage, unbalanced load distribution, constructional imperfections in the design of the primary and secondary windings, instrumentation differences (i.e., signal conditioning variance or sensor errors), and interturn short-circuit fault. If due to any of these reasons, for e.g. unbalance supply voltage, (let $Z_{a}=Z_{b}=Z_{c}$ and $\left(V_{1 a}-\right.$ $\left.\left.V_{1 l a}\right) \neq\left(V_{1 b}-V_{1 l b}\right) \neq\left(V_{1 c}-V_{1 l c}\right)\right)$ as shown in Fig. 1 (d), different transformer currents of the three-phase solidly ground and the $\mathrm{Y}-\mathrm{Y}$ connected system; and equation (6) is no longer valid. Therefore, equation (6) is written as follows:

$$
\frac{\boldsymbol{V}_{1 \boldsymbol{a}}-\boldsymbol{V}_{1 \boldsymbol{l a}}}{Z_{a}}+\frac{\boldsymbol{V}_{1 \boldsymbol{b}}-\boldsymbol{V}_{1 \boldsymbol{l} \boldsymbol{b}}}{Z_{b}}+\frac{\boldsymbol{V}_{1 \boldsymbol{c}}-\boldsymbol{V}_{1 \boldsymbol{l} \boldsymbol{c}}}{Z_{c}} \neq 0
$$

In order to compensate the source voltage imbalance condition, voltage correction coefficients $\alpha_{a}, \alpha_{b}$ and $\alpha_{c}$ are determined in every cycle of the output voltage by comparing individual phase voltages with their average values. The transformer winding once designed, remains unaltered unless any type of interturn fault occurs. The non uniform load distribution on different phases of the transformer is also considered as it produces the variation in load terminal voltage. For this load imbalance condition, one more set of correction coefficients are applied. These correction coefficients are $\beta_{a}, \beta_{b}$ and $\beta_{c}$ and are called as load coefficients. For this, it is essential to have knowledge about the load pattern on every phase of transformer. The constructional imbalance is also taken into account by applying another set of correction coefficients. These asymmetry correction coefficients are $\gamma_{a}, \gamma_{b}$ and $\gamma_{c}$. These are calculated only when commissioning the transformer by comparing individual phase currents with their average values. Thus, the inherent asymmetries of transformer as well as instrumentation differences can be compensated. All these correction coefficients are complex in nature and correct the magnitude of currents and phase angles. Therefore, the magnitude of currents and phase angles remains constant under healthy condition. Hence, (15) is written as

$\frac{\alpha_{a} \beta_{a} \gamma_{a}\left(\boldsymbol{V}_{1 a}-\boldsymbol{V}_{1 l a}\right)}{Z_{a}}+\frac{\alpha_{b} \beta_{b} \gamma_{b}\left(\boldsymbol{V}_{1 b}-\boldsymbol{V}_{1 l b}\right)}{Z_{b}}+\frac{\alpha_{c} \beta_{c} \gamma_{c}\left(\boldsymbol{V}_{1 c}-\boldsymbol{V}_{1 l c}\right)}{Z_{c}}=0$

Under balanced voltage condition of magnitude and phase, the locus of vector $\boldsymbol{i}_{\boldsymbol{a} \mathbf{1}}$ and $\boldsymbol{i}_{\boldsymbol{a} \mathbf{2}}$ (equation (14)) is plotted. It is found that the locus of $\boldsymbol{i}_{\boldsymbol{a} 1}$ is an ellipse and with anticlockwise rotation. While locus of vector $\boldsymbol{i}_{\boldsymbol{a} \mathbf{2}}$ is also an ellipse but the rotation is clockwise. Both these ellipses are exactly overlapping with each other and their centers are at one point as shown in Fig. 3(a). The major and minor axes of both the ellipses are coinciding with each other. The area of the ellipses indicates the percentage loading of the transformer. For no load condition, the elliptical area is smaller and it gradually increases as the transformer is loaded. In Fig. 3(a), the inner ellipses illustrate no load condition and the outer represents the rated load condition.

Whenever the interturn short circuit fault occurs, the value of current of that particular phase not only changes in magnitude but also in phase displacement with respect to voltage as given in (11). Hence, under abnormal conditions, the transformer current will get unbalanced and the locus of vector $\boldsymbol{i}_{\boldsymbol{a} 1}$ becomes more elliptical in shape with anticlockwise direction. The locus of vector $\boldsymbol{i}_{\boldsymbol{a} \mathbf{2}}$ also becomes more elliptical but the rotation is clockwise. These two ellipses are not overlapping with each other as their major and minor axes are not coinciding; thereby displacement angle $\varphi$ comes into existence between the cross section of two major axes of both ellipses. The centers of both the loci are same but due to displacement angle $\varphi$, the arc shapes on either side of the center are formed as shown in Fig. 3 (b). These arc shapes look like wings of the flying bird [14]. These wings are steady as displacement angle $\varphi$ is zero for healthy condition and their travel increases with the severity of faults. As, more numbers of turns shorted the magnitude of displacement angle $\varphi$ increases and their by the travel of the wings $\left(T_{w}\right)$ as well as area of travel of each wing $\left(A_{w}\right)$ also increases.

Due to existence of interturn faults, number of primary or secondary winding turns $\left(N_{1(a, b, c)} / N_{2(a, b, c)}\right)$ of any phase or phases gets shorted and the impedance deviation of winding $\left(\Delta Z_{w}\right)$ of that phase or phases increases. The change in magnitude of winding impedance deviation $\left(\Delta Z_{w}\right)$ causes the rise in transformer primary intake current by $I_{1 d} \angle \delta_{1}$. Therefore, displacement angle $\varphi$ depends upon the winding impedance deviation $\left(\Delta Z_{w}\right)$ and subsequently the current of that particular phase. The displacement angle $\varphi$ is directly proportional to winding impedance deviation $\left(\Delta Z_{w}\right)$ and inversely proportional to the phase current of particular phase or phases $\left(I_{1(a, b, c)}\right)$. Hence, the displacement angle $\varphi$ is a function of that phase current $\left(I_{1(a, b, c)}\right)$. These relations are expressed as following set of equations. 


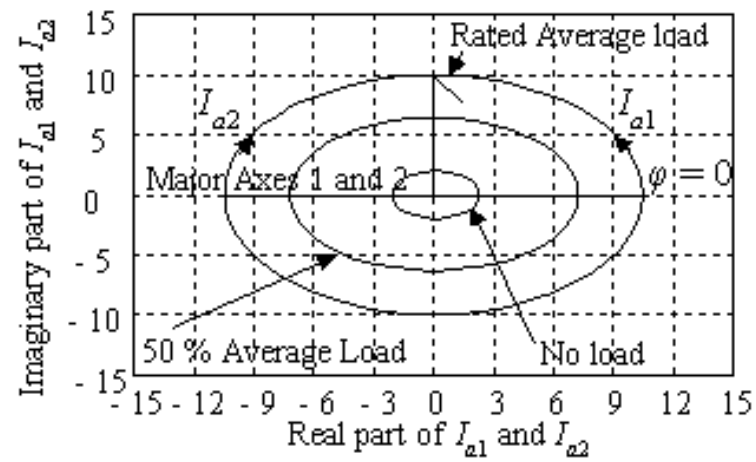

(a)

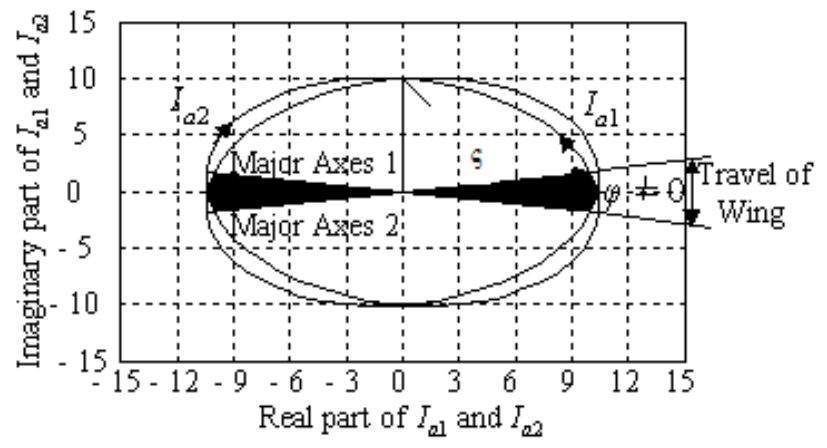

(b)

(Scale: X Axis 3 Ampere / Div. and Y Axis 5 Ampere / Div.)

Fig. 3. Basic idea of loci of $\boldsymbol{i}_{\boldsymbol{a} 1}$ and $\boldsymbol{i}_{\boldsymbol{a} \mathbf{2}}$ for (a) healthy transformer, (b) interturn short circuit fault in transformer.

$$
\begin{aligned}
& \phi=f_{1}\left(N_{1(a, b, c)} / N_{2(a, b, c)}\right) \\
& \phi=f_{2}\left(\Delta Z_{w}\right) \\
& \phi=f_{3}\left(I_{1(a, b, c)}\right) \\
& \phi=f_{4} \text { (severity of fault) }
\end{aligned}
$$

where functions $f_{1} \ldots f_{4}$ are different non-linear functions. The winding insulation becomes poor as more turns (primary or secondary sides or both) are shorted (17). Hence, the displacement angle $\varphi$ increases. The insulation condition of the winding $\left(N_{w}\right)$ is mentioned in terms of the displacement angle $\varphi$, wing travel $\left(T_{w}\right)$, and travel area of each wing $\left(A_{w}\right)$.

$$
N_{w}=f_{5}\left(\varphi, T_{w}, A_{w}\right)
$$

The travel of wing $\left(T_{w}\right)$ and area of travel $\left(A_{w}\right)$ of each wing are defined as follows.

$$
\begin{aligned}
& T_{w}=2 \varsigma \sin (\varphi / 2) \\
& A_{w}=\int_{\varsigma=0}^{\varsigma=R} \varsigma d \varsigma \int_{\varphi=0}^{\varphi=\Psi} d \varphi
\end{aligned}
$$

Where, $\varsigma=\sqrt{\varsigma_{x}+\varsigma_{y}}, \varsigma_{x}$ and $\varsigma_{y}$ are the cosine and sine components of radius $\varsigma$. It should be noticed from (20) that the radius $\varsigma$ equation depicts the load condition of the transformer, whereas the displacement angle $\varphi$ indicates the
TABLE I

POWER TRANSFORMER PARAMETERS

\begin{tabular}{|l|l|}
\hline Power rating & $7.5 \mathrm{kVA}$ \\
Voltage rating & $400 / 200 \mathrm{~V}$ \\
Rated Current Primary(A) & 10.82 \\
Frequency & $50 \mathrm{~Hz}$ \\
Three leg core type & \\
vector group & YNyn0 \\
Primary winding turns & 182 \\
Secondary winding turns & 91 \\
Voltage per turn & $1.268 \mathrm{~V}$ \\
Average flux density & $1.2 \mathrm{~T}$ \\
Magnetic Core & Cold \\
& laminated steel \\
\hline
\end{tabular}

severity of fault. The maximum value of $\varsigma=R$ and $\varphi=\Psi$ depends upon loading and severity of fault respectively. Therefore, the condition of transformer winding insulation $\left(N_{w}\right)$ can be predicted based upon the displacement $\varphi$, travel of wing $\left(T_{w}\right)$ and area of travel $\left(A_{w}\right)$. Under ideal condition, when the transformer winding is healthy, the displacement angle $\varphi$ is $0^{\circ}$ i.e., both the wings are in a straight line with $T_{w}$ $=0$ and area of travel $A_{w}=0$. But, in practice due to variation in supply voltage, inherent asymmetries of transformer, instrumentation differences, as well as due to non uniform load distribution displacement; $\varphi$ appears with a certain value close to about $0^{\circ}$ and the wing travel appears because of the variation in the supply voltage, inherent transformer asymmetries, instrumentation differences, and non-uniform load distribution displacement in practice. By contrast, the correction coefficients are applied in this system. Therefore, the displacement angle $\varphi$ is always $0^{\circ}$, and both wings are in a straight line under the healthy transformer condition.

\section{EXPERIMENTAL RESULTS}

A $7.5 \mathrm{kVA}, 400 / 200 \mathrm{~V}, \mathrm{Y}-\mathrm{Y}$ connected transformer is designed in the laboratory and its parameters are listed in Table I. For the experimental simulation of interturn short circuit faults, $5 \%$ turns of primary winding and $10 \%$ turns of secondary windings are taken out. The interturn short circuits are achieved using a variable $1 \Omega$ resistor. This resistor is used for safety purpose to avoid sparking at the time of making short. Finally, in the steady state, its value is reduced to zero. The functional block diagram and the photograph of the experimental setup are depicted in Fig. 4(a) and (b) respectively. The output of the transformer is connected to a bank of ten resistors that are individually controlled to provide a wide range of loads. The load pattern of this transformer is depicted in Fig. 5.

In this block diagram, the voltage and currents are sensed using Hall Effect voltage and current transducers, LEM LV 25-P and LEM LA 55-P respectively. The sampling 
Turns taken out for the purpose of shortening Primary Winding Secondary Winding

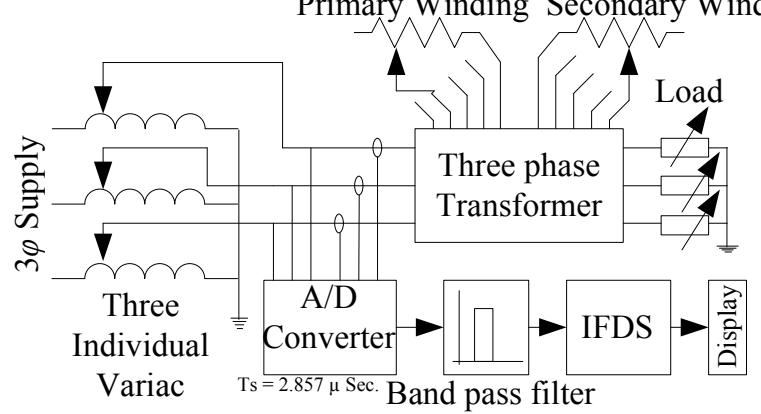

(a)

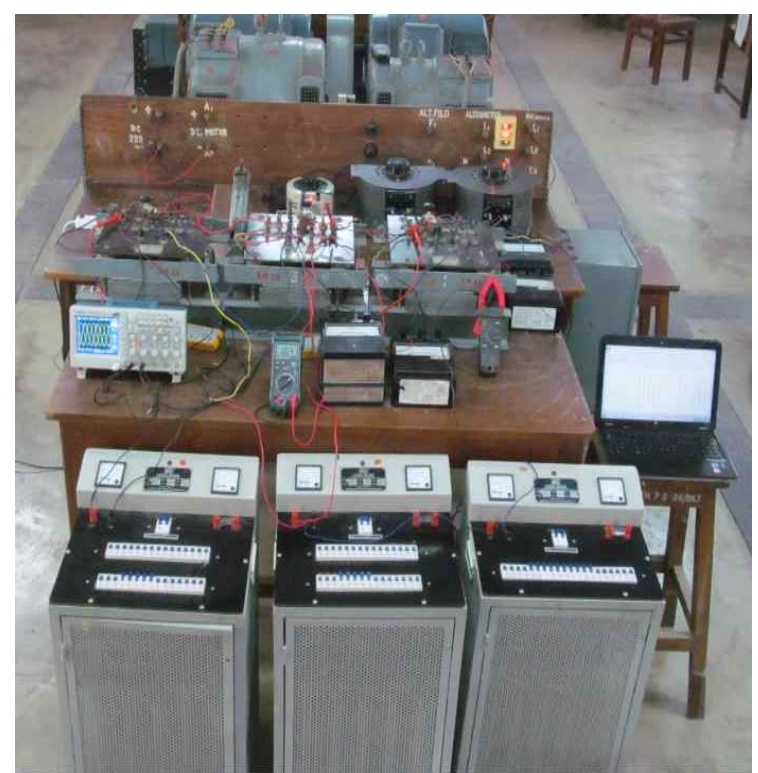

(b)

Fig. 4. (a) Functional Block diagram. (b) Photograph of the experimental setup.

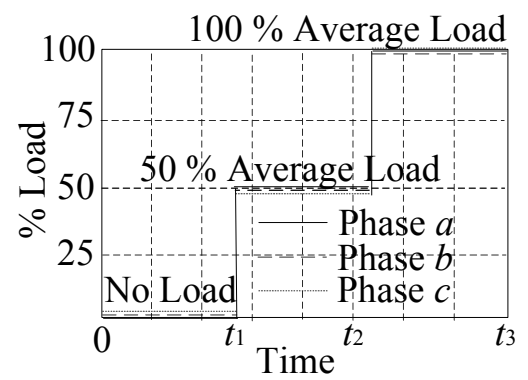

Fig. 5. Transformer load profile for experimentation.

frequency of analog to digital converter is $350 \mathrm{kHz}$. The voltage correction coefficients are computed within consecutive cycles of the primary voltage and are applied to respective phases.

The asymmetry correction coefficients are calculated by short circuit test and are applied to compensate errors due to constructional imbalance and instrumentation differences.
TABLE II

LOAD COEFFICIENTS

\begin{tabular}{|c|c|c|c|}
\hline $\begin{array}{l}\text { Load } \\
\text { coefficients }\end{array}$ & No load & $\begin{array}{l}50 \% \text { rated } \\
\text { average } \\
\text { load }\end{array}$ & $\begin{array}{l}100 \% \text { rated } \\
\text { average load }\end{array}$ \\
\hline$\beta_{a}$ & $\begin{array}{l}1.07187- \\
\text { j0.2176 }\end{array}$ & $\begin{array}{l}0.9773-\mathrm{j} \\
0.1392\end{array}$ & $\begin{array}{l}0.9800-\mathrm{j} \\
0.1989\end{array}$ \\
\hline$\beta_{b}$ & $\begin{array}{l}0.9625-\mathrm{j} \\
0.1371\end{array}$ & $\begin{array}{l}0.9836+\mathrm{j} \\
0.1997\end{array}$ & $\begin{array}{l}1.0086+ \\
0.1437\end{array}$ \\
\hline$\beta_{c}$ & $\begin{array}{l}0.9364+\mathrm{j} \\
0.1334\end{array}$ & $\begin{array}{l}0.9891-\mathrm{j} \\
0.2008\end{array}$ & $\begin{array}{l}0.972- \\
0.1385\end{array}$ \\
\hline
\end{tabular}

These asymmetry correction coefficients calculated for the transformer pertaining to primary side are $\gamma_{a}=1.003+\mathrm{j} 0.12$, $\gamma_{b}=0.974+\mathrm{j} 0.28$ and $\gamma_{c}=0.991+\mathrm{j} 0.006$ for the respective phases. These coefficients take care of constructional asymmetry of transformer and errors due to signal conditioning of the meters under performance.

The supply voltage on the primary side should be $V_{a}=231 \quad \angle \quad 0^{\circ}, \quad V_{b}=231 \quad \angle \quad-120^{\circ}, \quad$ and $\boldsymbol{V}_{c}=231 \angle+120^{\circ} \mathrm{V}$ under the normal condition for a $400 \mathrm{~V}$, three-phase, $\mathrm{Y}-\mathrm{Y}$ connected power transformer. However, the three-phase voltage sources for this experimentation are adjusted using three individual auto transformers as $V_{a}=228 \quad \angle \quad 4^{\circ}, \quad V_{b}=231 \quad \angle \quad-120^{\circ}-3.5^{\circ}, \quad$ and $\boldsymbol{V}_{c}=234 \angle+120^{\circ}+2.5^{\circ} \mathrm{V}$. Hence, imbalance occurs in this case because of the magnitude and the phase displacement. This imbalance is compensated by obtaining and applying the voltage correction coefficients. Therefore, the voltage correction coefficients computed and applied for this instance are $\alpha_{a}=1.010689893-\mathrm{j} .070674322, \alpha_{b}=0.998134798-\mathrm{j}$ 0.061048539 , and $\alpha_{c}=0.986239911-\mathrm{j} 0.043060164$ for the three phases, respectively. These voltage coefficients address the conditions because of the source voltage variations.

The developed wing technique is immune to load variations. The average load current of all the three phases is determined for the computation of the load coefficients. The load coefficients obtained for different load conditions are tabulated in Table II. The experimental simulation for the interturn short-circuit fault is made possible in this study by shorting the relevant turn of the respective phase for the primary and secondary sides. The three-phase line currents of the transformer under the healthy and different primary and secondary interturn fault conditions at $100 \%$ rated average load are presented in Figs. 6(a)-6(d). The interturn fault is conducted earlier on the primary side of the phase- $a$ transformer by shorting the turns. $i_{1 a f}$ and $i_{1 c f}$ represent the fault currents when the interturn faults are experimentally created on phases- $a$ and $-c$ of the primary and secondary windings, respectively (Fig. 6(d)). The transformer is initially 


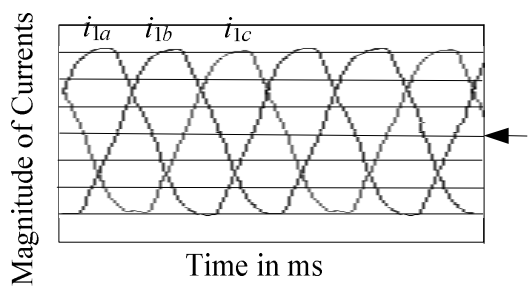

(a)

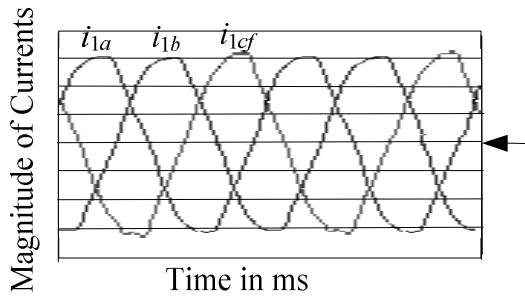

(c)

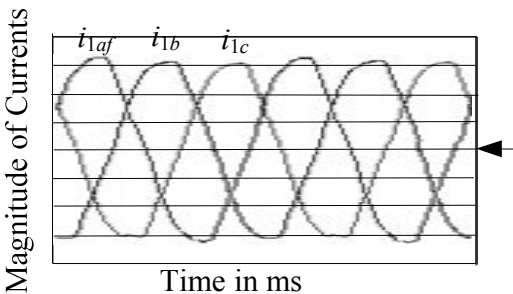

(b)

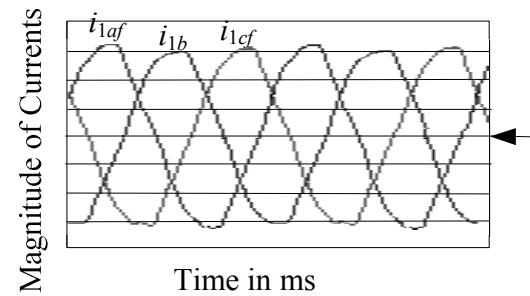

(d)

(Scale: 5 A./division)

Fig. 6. Experimental waveform of line currents for the transformer at $100 \%$ average rated load (a) healthy condition; interturn fault condition (b) when $5 \%$ turns of primary phase- $a$ shorted, (c) when $10 \%$ turns of secondary phase- $c$ shorted, (d) when $5 \%$ turns of primary phase- $a$ and $10 \%$ turns of secondary phase- $c$ shorted.

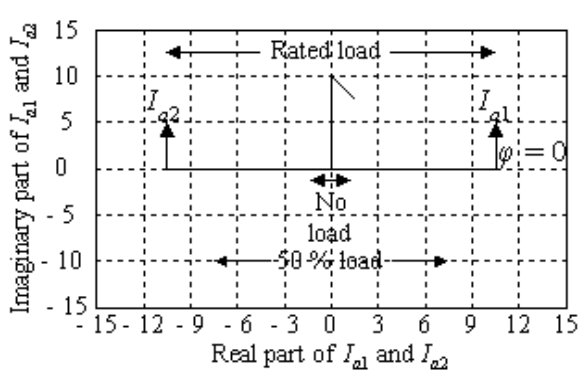

(a)

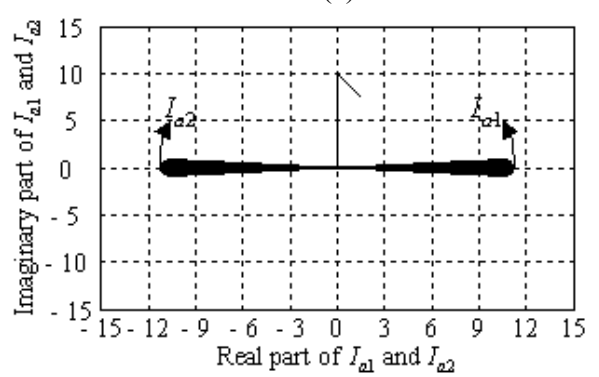

(c)

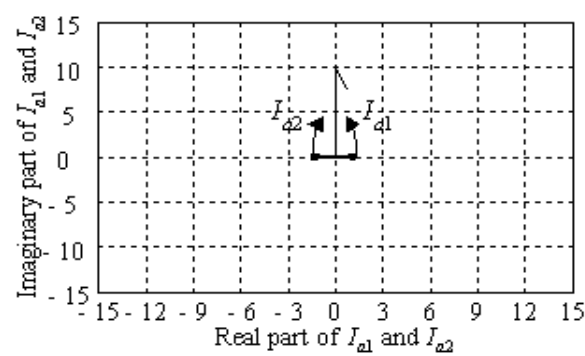

(e)

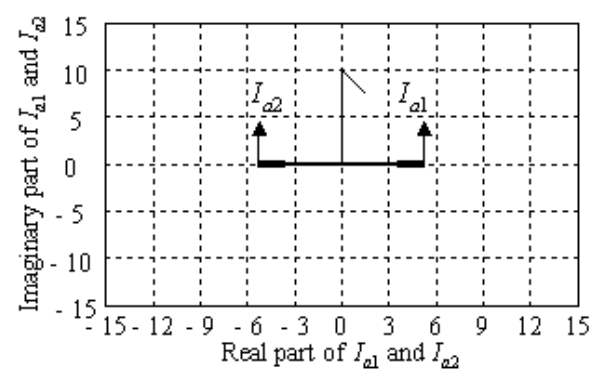

(b)

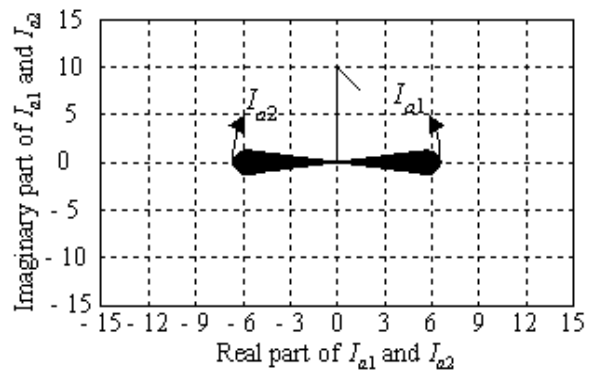

(d)

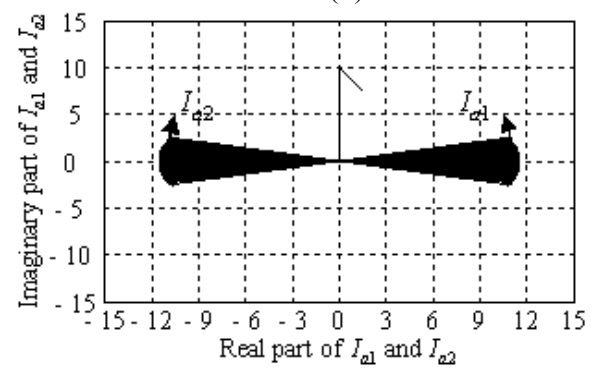

(f)

Fig. 7. Wing loci of currents $\boldsymbol{i}_{\boldsymbol{a} 1}$ and $\boldsymbol{i}_{\boldsymbol{a} \mathbf{2}}$ for: (a) healthy winding condition at different loads; (b) $5 \%$ turns of the primary shorted at $50 \%$ rated average load; (c) $5 \%$ turns of the primary shorted at $100 \%$ rated average load; (d) $10 \%$ turns of the secondary shorted at $50 \%$ rated average load; (e) $5 \%$ turns of the primary and $10 \%$ turns of the secondary shorted at the no-load condition; and (f) $5 \%$ turns of the primary and $10 \%$ turns of the secondary shorted at $100 \%$ rated average load. 
TABLE III

COMPARISON OF INTERTURN FAULTS AND LOAD CONDITIONS

\begin{tabular}{|c|c|c|c|c|c|}
\hline \multirow{2}{*}{$\begin{array}{l}\mathrm{T} / \mathrm{f} \text { side } \\
\text { and its } \\
\text { phase }\end{array}$} & \multirow{2}{*}{$\begin{array}{l}\text { Turns } \\
\text { shorted }\end{array}$} & \multirow[b]{2}{*}{$\begin{array}{l}\text { Observed } \\
\text { parameters }\end{array}$} & \multicolumn{3}{|c|}{ Average load conditions } \\
\hline & & & $\begin{array}{l}\text { No } \\
\text { load }\end{array}$ & $50 \%$ & $100 \%$ \\
\hline \multirow{3}{*}{$\begin{array}{l}P(a, b, c) \\
S(a, b, c)\end{array}$} & \multirow{3}{*}{0} & $\begin{array}{l}\varphi \\
\text { Degrees }\end{array}$ & 0 & 0 & 0 \\
\hline & & $T_{w}$ in $\mathrm{A}$ & 0 & 0 & 0 \\
\hline & & $A_{w}$ in $\mathrm{A}^{2}$ & 0 & 0 & 0 \\
\hline \multirow{3}{*}{$P(a)$} & \multirow{3}{*}{$5 \%$} & $\begin{array}{ll}\varphi & \text { in } \\
\text { Degrees }\end{array}$ & 0.94 & 1.6 & 2.7 \\
\hline & & $T_{w}$ in $\mathrm{A}$ & 0.011 & 0.301 & 1.015 \\
\hline & & $A_{w}$ in $\mathrm{A}^{2}$ & 0.002 & 0.814 & 5.496 \\
\hline \multirow{3}{*}{$S(c)$} & \multirow{3}{*}{$10 \%$} & $\begin{array}{l}\varphi \\
\text { Degrees }\end{array}$ & 8.8 & 5.6 & 11.6 \\
\hline & & $T_{w}$ in $\mathrm{A}$ & 0.107 & 1.053 & 4.342 \\
\hline & & $A_{w}$ in $\mathrm{A}^{2}$ & 0.019 & 2.85 & 23.614 \\
\hline \multirow[t]{3}{*}{$P(a)$} & \multirow[t]{3}{*}{$5 \%$} & $\begin{array}{ll}\varphi & \text { in } \\
\text { Degrees }\end{array}$ & 8.2 & 6.8 & 13.7 \\
\hline & & $T_{w}$ in A & 0.1 & 1.279 & 3.461 \\
\hline & & $A_{w}$ in $\mathrm{A}^{2}$ & 0.018 & 3.461 & 27.889 \\
\hline
\end{tabular}

under the healthy condition. The positive and negative sequence components (i.e., currents $\boldsymbol{i}_{\boldsymbol{a} 1}$ and $\boldsymbol{i}_{\boldsymbol{a} 2}$ ) for each set of collected data are calculated using equation (14). The wing shapes are plotted using the real and the imaginary parts of the sequence currents. The displacement angle $\varphi$ is obtained from the loci of $\boldsymbol{i}_{\boldsymbol{a} 1}$ and $\boldsymbol{i}_{\boldsymbol{a} \mathbf{2}}$. The interturn fault detection system (IFDS) program, which performs the necessary calculations and plots the loci of $\boldsymbol{i}_{\boldsymbol{a} 1}$ and $\boldsymbol{i}_{\boldsymbol{a} 2}$, is developed in $\mathrm{C \#}$. The IFDS program also computes the displacement angle $\varphi$, wing travel $\left(T_{\mathrm{w}}\right)$, and travel area $\left(A_{\mathrm{w}}\right)$.

The wing size obtained from the loci of currents $\boldsymbol{i}_{\boldsymbol{a} 1}$ and $\boldsymbol{i}_{\boldsymbol{a} \mathbf{2}}$ corresponding to a healthy transformer at no load, $50 \%$ load, and $100 \%$ average load conditions is presented in Fig. 7(a). A large size or length of wings corresponds to great load on the transformer. The outer loci of currents $\boldsymbol{i}_{\boldsymbol{a} 1}$ and $\boldsymbol{i}_{\boldsymbol{a} 2}$ for the $100 \%$ load condition in Fig. 7(a) correspond to the currents presented in Fig. 6(a). The interturn short-circuit fault is experimentally created by adjusting the rheostat of $1 \Omega$ of the respective winding in the primary and secondary sides of the transformer. The major axes of the loci of currents $\boldsymbol{i}_{\boldsymbol{a} \mathbf{1}}$ and $\boldsymbol{i}_{\boldsymbol{a} \mathbf{2}}$ do not coincide. Moreover, the displacement $\varphi$ is not equal to $0^{\circ}$. The displacement angle $\varphi$ is $1.6^{\circ}$ and $2.7^{\circ}$ when $5 \%$ turns of the primary is shorted at $50 \%$ and $100 \%$ rated average loads, respectively [Fig. 7(b) and (c)]. The respective wing travel is $0.301 \mathrm{~A}$ to $1.015 \mathrm{~A}$, and the wing area increases from $0.814 \mathrm{~A}^{2}$ to $5.496 \mathrm{~A}^{2}$. The displacement $\varphi$ is $5.6^{\circ}$ when $10 \%$ turns of the secondary winding pertaining to phase- $c$ is shorted at $50 \%$ rated average load as shown in Fig. 7(d). The wing travel $\left(T_{w}\right)$ for this kind of fault is $1.053 \mathrm{~A}$, and the travel area $\left(A_{w}\right)$ is $2.85 \mathrm{~A}^{2}$.

The interturn short-circuit fault is created by adopting the similar procedure on the windings of both sides of the transformer. The displacement $\varphi$ is $8.2^{\circ}$, wing travel is $0.1 \mathrm{~A}$, and wing area is $0.018 \mathrm{~A}^{2}$ when the faults are created by creating the interturn short circuit faults on both sides of the transformers under the no-load condition. This fault situation is depicted in Fig. 7(e). The displacement $\varphi$ shifts to $13.7^{\circ}$, wing travel increases to $3.461 \mathrm{~A}$, and wing area increases to $27.889 \mathrm{~A}^{2}$ when the similar fault is experimentally created under the $100 \%$ average load condition. This fault situation is depicted in Fig. 7(f).

Table III illustrates a comparison for different fault conditions. Letters $P$ and $S$ indicate the primary and secondary sides of the transformer, respectively. This tabulated comparison indicates that the displacement angle $\varphi$, wing travel $\left(T_{w}\right)$, and wing travel area $\left(A_{w}\right)$ are all at zero value under the no-fault or healthy condition. These values gradually increase with the severity of faults. The experimental results indicate the strength and fidelity of the method.

\section{CONCLUSIONS}

This paper extends the wing technique to detect the interturn short-circuit fault in the three-phase transformer. These faults are experimentally created on the primary, secondary, and both sides of a three-phase transformer. The presented results are confirmed under various source voltage and load imbalance conditions. The proposed scheme is immune to voltage variation and load imbalance, and considers inherent asymmetry and measurement errors. The correction coefficients $(\alpha, \beta$, and $\gamma)$ compensate these non-linearities.

The wing shape and size provide a definite correlation with the winding insulation condition and lead to improvement in the reliability, efficiency, and safety of the transformer.

\section{REFERENCES}

[1] A. Abu-Siada and S. Islam, "A novel online technique to detect power transformer winding faults," IEEE Trans. Power Delivery, Vol. 27, No. 2, pp.849-857, Apr. 2012.

[2] V. Behjat and A. Vahedi, "Numerical modelling of transformers interturn faults and characterising the faulty transformer behaviour under various faults and operating conditions," IET Electric Power Applications, Vol. 5, No. 5, pp. 415-431, May 2011.

[3] O. E. Gouda1, A. Z. E. Dein, and I. Moukhtar, "Turn-to-earth fault modelling of power transformer based on symmetrical components," IET Generation Transmission Distribution, Vol. 7, No. 7, pp. 709-716, Jul. 2013.

[4] Y.-C. Kang, B.-E. Lee, T.-Y. Zheng, Y.-H. Kim, and P.A. Crossley, "Protection, faulted phase and winding identification for the three-winding transformer using the increments of flux linkages," IET Generation Transmission Distribution, Vol. 4, No. 9, pp. 1060-1068, Sep. 2010.

[5] M. Bagheri, M. S. Naderi, and T. Blackburn, "Advanced transformer winding deformation diagnosis: moving from 
off-line to on-line," IEEE Trans. Dielectr. Electr. Insul., Vol. 19, No. 6, pp. 1860-1870, Dec. 2012.

[6] V. Behjat, A. Vahedi, A. Setayeshmehr, H. Borsi, and E. Gockenbach, "Sweep frequency response analysis for diagnosis of low level short circuit faults on the windings of power transformers: An experimental study," Journal of Electrical Power and Energy Systems, Vol. 42, No. 1, pp. 78-90, Nov. 2012.

[7] M. S. Naderi, G. B. Gharehpetian, M. Abedi, and T. R. Blackburn, "Modelling and detection of transformer internal incipient fault during impulse test," IEEE Trans. Dielectr. Electr. Insul., Vol. 15, No. 1, pp. 284-291, Feb. 2008.

[8] G. D. González, J. G.-A. Fernández, and P. A. Arboleya, "Diagnosis of a turn-to-turn short circuit in power transformers by means of zero sequence current analysis," Electric Power Systems Research, Vol. 69, No. 2-3, pp. 321-329, May 2004.

[9] L. M. R. Oliveira, A. J. M. Cardoso, and S. M. A. Cruz, "Power transformers winding fault diagnosis by the on-load exciting current extended Park's vector approach," Electric Power Systems Research, Vol. 81, No. 6, pp. 1206-1214, Jun. 2011.

[10] V. Behjat, A. Vahedi, A. Setayeshmehr, H. Borsi, and E. Gockenbach, "Diagnosing shorted turns on the windings of power transformers based upon online FRA using capacitive and inductive couplings," IEEE Trans. Power Del., Vol. 26, No. 4, pp.2123-2133,Oct. 2011.

[11] X. Lei, J. Li, Y. Wang, S. Mi, and C. Xiang, "Simulative and experimental investigation of transfer function of inter-turn faults in transformer windings," Electric Power Systems Research, Vol. 107, pp. 1-8, Feb. 2014.

[12] V. Behjat and A. Vahedi, "An experimental approach for investigating low-level interturn winding faults in power transformers," Electrical Engineering, Vol. 95, No. 2, pp 135-145, Jun. 2013.

[13] L. M. R. Oliveira and A. J. M. Cardoso, “A permeance based transformer model and its application to winding interturn arcing fault studies," IEEE Trans. Power Del., Vol. 25, No. 3, pp. 1589-1598, Jul. 2010.

[14] M. S. Ballal, D. M. Ballal, H. M. Suryawanshi, and M. K. Mishra, "Wing technique: A novel approach for the detection of stator winding inter-turn short circuit and open circuit faults in three phase induction motors," Journal of Power Electronics, Vol. 12, No. 1, pp. 208-214, Jan. 2012.

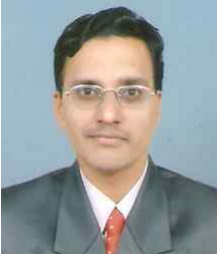

Makarand Sudhakar Ballal was born in Nagpur, India. He received his B.E. in Electrical Engineering from Marathwada University, Aurangabad, India in 1993. He received his M.Tech. and Ph.D. in Electrical Engineering from Nagpur University, Nagpur, India, in 1997 and 2007, respectively. From 1997 to 2012, he was with Maharashtra State Electricity Transmission Company Limited, Maharashtra, India, where he worked on the commissioning, installation, and testing of various $\mathrm{HV}$ and $\mathrm{EHV}$ electrical equipment and accessories. $\mathrm{He}$ was a member of the research and development committee of Maharashtra State Electricity Transmission Company Limited, Maharashtra, India. He is currently an associate professor in the Department of Electrical Engineering, Visvesvaraya National Institute of Technology, Nagpur, India. His current research interests include condition monitoring and fault diagnosis of electrical machines.

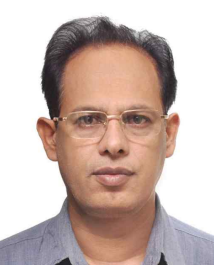

Hiralal Murlidhar Suryawanshi was born in India in 1963. He received his B.E. from Shivaji University, Kolhapur, India, in 1988. $\mathrm{He}$ received his M.E. in Electrical Engineering from the Indian Institute of Science, Bangalore, in 1994 and his Ph.D. in Electrical Engineering from Nagpur University, Nagpur, India, in 1999. Since 2007, he has been an professor in the Department of Electrical Engineering, Visvesvaraya National Institute of Technology, Nagpur, India. He is the associate editor of IEEE Transactions on Industrial Electronics. His current research interests include power electronics, drives, and condition monitoring of electrical equipment.

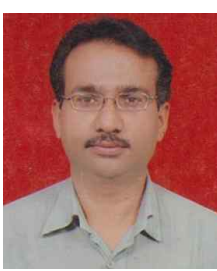

Bhupesh Nemichand Choudhari was born in Aurangabad, India. He received his B.E and M.E. in Electrical Engineering from Marathwada University, Aurangabad, India, in 1993 and 2000, respectively. He is currently an associate professor in the Department of Electrical Engineering, P.E.S. College of Engineering, Aurangabad, India. His current research interests include condition monitoring and fault diagnosis of electrical machines. 